\title{
The Relative Age Effect on Soccer Players in Formative Stages with Different Sport Expertise Levels
}

\author{
by \\ Alba Práxedes ${ }^{1}$, Alberto Moreno ${ }^{1}$, Luis García-González², \\ David Pizarro ${ }^{1}$,Fernando Del Villar ${ }^{3}$
}

\begin{abstract}
The Relative Age Effect (RAE) in sport has been targeted by many research studies. The objective of this study was to analyze, in amateur clubs, the RAE of soccer players, according to the sport expertise level of the team (e.g., $A$, $B, C$ and subsequent) that they belong to within the same game category. 1,098 soccer players in formative stages took part in the study, with ages varying between 6 and 18 years old (U8 to U19 categories). All of them were members of 4 Spanish federated clubs. The birth dates were classified into 4 quartiles $(Q 1=J a n-M a r ; Q 2=A p r-J u n ; Q 3=J u l-S e p t ;$ $Q 4=$ Oct-Dec) according to the team they belonged to. The results obtained in the chi-squared test and $d$ value (effect size) revealed the existence of RAE in the teams with the highest expertise level, " $A$ " (X2 $=15.342, p=.002, d=$ $0.4473)$ and " $B$ " $(X 2=10.905, p=.012, d=0.3657)$. However, in the lower level teams, " $C$ and subsequent", this effect was not observed. Present findings show that players born during the first months of the year tend to be selected to play in teams with a higher sport expertise level of each category, due to their physical maturity. Consequently, this causes differences in terms of the experience they accumulate and the motivation that this creates in these players.
\end{abstract}

Key words: relative age effect, sports training, soccer, talent identification.

\section{Introduction}

To guarantee equality in competition and provide young people with the same success opportunities, in sport, athletes are grouped into different game categories based on their chronological age (Musch and Groundin, 2001). However, using this criterion does not seem adequate given that there is 12 months' difference between the youngest and the oldest athletes. In this sense, and because considerable anthropometric and physiological changes take place during adolescence, an athlete born in January (relatively older) will have one year's advantage over another athlete born in December (relatively younger) (Arrieta et al., 2015). The consequence of this, translated into the tendency to choose the oldest players in each category, is known as the Relative Age Effect (RAE) (Gil et al., 2014).

The RAE has been studied in different sports such as hockey (Nolan and Howell, 2010), rugby (Till et al., 2009), volleyball (Okazaki et al., 2011) and especially in soccer (Gil et al., 2007; Sallaoui et al., 2014). In soccer, numerous studies focused on the RAE have determined that players born during the first months of the year are identified with success in this sport (Augste and Lames, 2011; Helsen et al., 2005; Van den Honert, 2012). Hence, clubs with prestige or characterized by playing in higher leagues select these players. However, in soccer, this selection process is not only perceived among clubs, but also among teams with different levels within the same

1 - Faculty of Sport Sciences, University of Extremadura, Cáceres, Spain.

2 - Faculty of Health and Sport Sciences, University of Zaragoza, Huesca, Spain.

3 - Sport Studies Center, University Rey Juan Carlos, Madrid, Spain. 
category (e.g., team A, team B, team C, etc.) (González-Víllora et al., 2015).

In this sense, a player selected for team A will play in different tournaments and competitions than a player in team $\mathrm{C}$, and will also, in turn, play against the most competitive teams of their category (Helsen et al., 2005). The latter positively determines the player's development. In this regard, Díaz del Campo et al. (2010) and Romann and Fuchslocher (2011) point out that these players, who were born during the first months of the year, have more experience and have trained for more hours. Furthermore, it is normal for the best teams to train with best coaches, play with high level athletes and participate in most prestigious competitions (Figueiredo et al., 2009), all of which provides them with advantages in performance and in future selections (Augste and Lames, 2011). Additionally, Helsen et al. (2005) point out that this selection increases both the players' intrinsic (perceived competence) and extrinsic (appreciation by coaches and parents) motivation, as it encourages them to improve their skills. This becomes a vicious circle where children born at the beginning of the year seem to have a great advantage, in terms of sports performance, over those born at the end of the year.

Considering the reasons for this selection, Augste and Lames (2001) reached a conclusion that the search for short-term performance and success prevailed in formative categories. These authors indicated that coaches, instead of trying to identify more talented players who can provide them with better results in the future, selected those born in the first quartile. In addition to this, nowadays, both club coaches and directors, as well as the players' parents, are more oriented towards competitive, instead of formative sport, from the very early age. Thus, we may notice how children born at the end of the year spend less time on the playing field during matches (Díaz del Campo et al., 2010; Romann and Fuchslocher, 2011). Studying this question in even greater depth, Kirkendall (2014) pointed out that initiation of sport should be an opportunity for young players to improve their skills, increase their tactical awareness, improve fitness, and enjoy playing with others of the same level.

Although there are numerous studies that have analyzed RAE in different sports such as soccer (González-Víllora et al., 2015), basketball (Saavedra et al., 2015) or volleyball (Okazaki et al., 2011), and tried to establish its relationships with maturation and anthropometry (Lovell et al., 2015) or physical performance characteristics (Haddad etl., 2015), only few studies have analyzed RAE in teams with a different sport expertise level within one age category (Gutiérrez et al., 2010). Thus, we considered it important to continue this research direction examining the reserves of soccer clubs, as it would provide valuable information for club directors and coaches. Therefore, the objective of this study was to analyze, in amateur clubs, the RAE of soccer players, according to the sport expertise level of the team they belonged to within the same age category.

\section{Methods}

Participants

A total of 1,098 soccer players in formative stages, with ages varying between 6 and 19 (U8, U10, U12, U14, U16 and U19 categories) participated in the study. All players belonged to 4 Spanish federated clubs, of which main teams were in the $3^{\text {rd }}$ division or in a lower category (amateur clubs). The selected clubs were located in medium-sized towns (50,000 - 100,000 inhabitants) and their players were recruited from the youth from the actual town. Thus, there was very little player mobility among the different clubs.

\section{Variables}

The independent variable considered in the study was the team's sport expertise level that was determined based on whether the players belonged to teams A, B or C, in each age category. The criterion used by amateur soccer clubs in Spain was followed, i.e., the players were distributed according to their expertise level and experience in the particular category. The best players were assigned to teams A and B, and their training was performance-oriented, while players not selected for these teams in their category were assigned to teams $C$ and their training was rather recreational and education-oriented.

Hence, the following classification of the sport expertise level was used in this study:

1. High expertise level teams, teams $A$, in each age category, consisted of players selected with performance objectives, and with one 
year experience in the category.

2. Intermediate expertise level teams, teams B, in each age category, were comprised of players also selected with performance objectives, although without any experience in the category.

3. Low expertise level teams, teams $C$, in each age category, included players who had not been selected as the best of their category, and whose participation in the club was recreation and education-oriented.

\section{Procedures}

Firstly, the distribution of the birth dates of players in the 2015/2016 season was analyzed. The data on birth dates were provided by the directors of the clubs and the players were divided into groups according to their month of birth. Following the guidelines of the Féderation Internationale de Football Association (FIFA), since 1997, the 1st of January is the start of the selection year, and this therefore is the cut-off date for the soccer competition year. Thus, January would be the first month of the selection year, and December the last. Therefore, players located in quartile $1(\mathrm{Q} 1)$ are those born between January and March, in quartile 2 (Q2), those born from April to June, in quartile 3 (Q3), from July to September, and in quartile $4(\mathrm{Q} 4)$, from October to December.

\section{Statistical analysis}

The asymmetry measures, kurtosis and Kolmogorov-Smirnov with Lilliefors correction test were employed to establish that the sample did not present a normal distribution, justifying the need to use non-parametric statistics. Then, a chi-squared test was performed to compare the relative age quartiles according to the team. Since the chi-squared test did not reveal the magnitude or direction of the existing relationship, Cohen's effect size was calculated in order to examine the differences between the teams and .20 was considered a small effect size, .50 medium and .80 large (Kraemer and Kupfer, 2006). All the analyses were performed with the SPSS 19.0 program, and statistical significance was set at $p<$ 0.05 .

\section{Results}

Table 1 and Figure 1 show the distribution of birth dates according to the sport expertise level of the team (A, B and C). As we can see, the distribution was unequal depending on the quartile when the players were born. However, the distribution of the birth dates was only significantly different in teams A and B (highlevel and intermediate level, respectively). Between 30 and $35 \%$ of the players of these teams were born in Q1, and between 25 and 30\% in Q2. Such differences were not observed in the third group (C), and the percentages were similar among the four quartiles. To study the RAE in greater depth, the calculation of effect size $d$ was considered, verifying that, in teams A and $\mathrm{B}$, the effect had intermediate magnitude, although this was slightly greater in teams A compared with teams B.

Table 1

Distribution of birth dates and relative age effect size of soccer players according to the team level.

\begin{tabular}{|c|c|c|c|c|c|c|c|c|}
\hline \multirow{2}{*}{ Team } & \multicolumn{5}{|c|}{ Number \& $\%$ of players per quartile } & \multirow{2}{*}{$\mathrm{X}^{2}$} & \multirow{2}{*}{$p$} & \multirow{2}{*}{$\begin{array}{c}\text { Effect size } \\
\quad(d)\end{array}$} \\
\hline & Q1 (\%) & Q2 (\%) & Q3 (\%) & Q4 (\%) & $\begin{array}{c}\text { Tota } \\
1 \\
\end{array}$ & & & \\
\hline A & $107(33.2)$ & $85(26.4)$ & $69(21.4)$ & $61(18.9)$ & 322 & 15.342 & .002 & .4473 \\
\hline B & $107(31.8)$ & $86(25.5)$ & $79(23.4)$ & $65(19.3)$ & 337 & 10.905 & .012 & .3657 \\
\hline $\mathrm{C}$ and subseq. & $110(24.5)$ & $116(25.8)$ & 117 (26.1) & 106 (23.6) & 449 & .719 & .869 & .0801 \\
\hline
\end{tabular}

Note. $\mathrm{Q} 1-\mathrm{Q} 4=$ birth quartiles $1-4 ; \mathrm{X}^{2}=$ Chi-square value; $p=$ significance. 


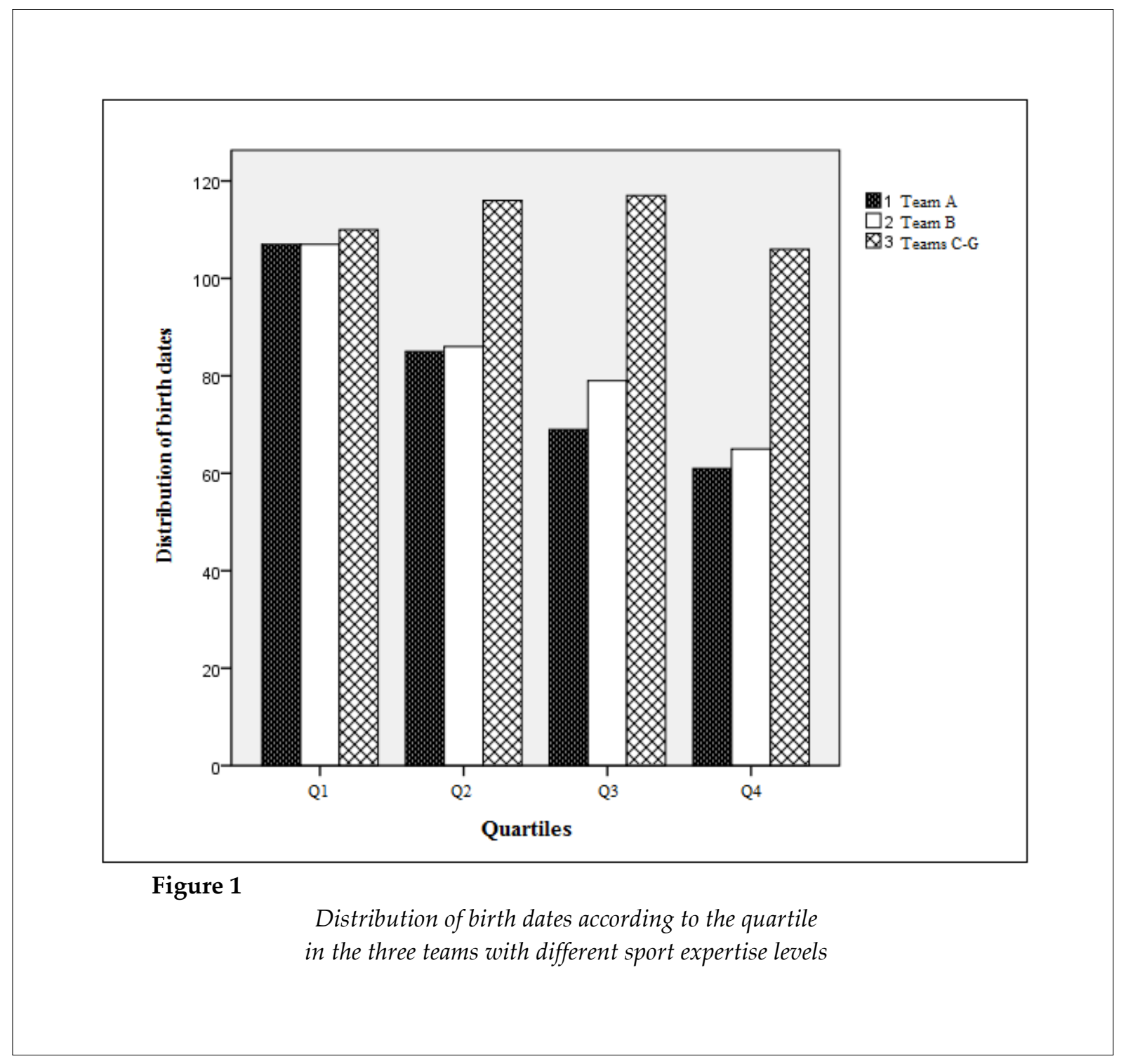

\section{Discussion}

The purpose of the study was to analyze the RAE of soccer players from amateur clubs, according to the sport expertise level of the team they belonged to within the same category. The obtained results show that in the lower categories of the four Spanish federated clubs, only the highlevel and intermediate-level teams $\mathrm{A}$ and $\mathrm{B}$ presented significant differences between the different quartiles, the percentage of players born in Q1 being higher. Therefore, it can be pointed out that RAE occurs in these teams. These findings confirm that RAE still constitutes a problem in team sports (Delorme and Raspaud, 2008; Till et al., 2010). This phenomenon is due to the fact that nowadays, the search for immediate performance prevails over the identification of talent, of which objective is to achieve more longterm results (Augste and Lames, 2011). Thus, in formative categories, players born at the beginning of the year (relatively older) have more advantages when the time of selection compared to those born at the end of the year (relatively younger), because physical, physiological and psychological development is more advanced in the former (Musch and Grondin, 2001). In this regard, it appears that maturity is one of the factors that most determines the selection processes of soccer players, and their consequent formation.

By studying in greater depth the differences found between particular teams according to the sport expertise level (A, B and C), 
with regard to higher- and intermediate-level teams (A and $\mathrm{B})$, the obtained results seem to indicate that these clubs select players born during the first months of the year, who are characterized by a greater physiological and anthropometric development (Delorme and Raspaud, 2008). However, in team C, such a phenomenon was not observed. Considering this perspective, only a small number of studies have analyzed this problem. More specifically, Gutiérrez et al. (2010) did not find any significant differences between teams A, B and C, observing that the percentage of players in each quartile was the same in all of them, being much greater in Q1 than the others quartiles. Thus, the RAE occurred in all teams. However, in our study we did find differences between the different teams. A possible explanation of the differences between the teams, found in our research, is that the young soccer players participating in the study belonged to the lower categories of clubs that competed in the $3^{\text {rd }}$ division leagues or lower, unlike the study by Gutiérrez et al. (2010), in which all teams belonged to the Professional Football League. In this sense, as these clubs were in higher leagues and located in bigger cities, they had more possibilities of finding and selecting players born during the first months of the year. In contrast, clubs included in this study belonged to lower level leagues and were located in smaller towns, thus, the selection process was limited to the youth from their actual town (Idafe, 2008). On the other hand, another possible explanation to the differences found between our research and that of Gutiérrez et al. (2010), may be that the reserve teams that belonged to lower leagues and had less prestige, included both teams directed at seeking performance (A and B) as well as teams directed at promoting sport (C), in which the RAE was not observed.

The consequences of RAE on the formation of young soccer players must be pointed out, in such a way that, in agreement with the theory of deliberate practice, players born during the first months and who are selected by the best teams of each category, benefit from a larger number of training hours (Díaz del Campo et al., 2010; Romann and Fuchslocher, 2011). In this sense, the experience they accumulate is greater than that of the other players, providing them with advantages in achieving peak performance (Ward and Williams, 2003; Ward et al., 2004), since, as indicated by the theory of deliberate practice, there is a significant positive relationship between practice and performance (Ericsson et al., 2006). In this regard, anthropometric characteristics are not the only decisive factors in the selection of players, as, considering their progress through the age categories, the fact that particular players have been selected for the best teams means that the effect of experience begins to become relevant.

This, in turn, creates an increase in the player's motivation (González-Víllora et al., 2015), which may be translated into greater effort and confidence. On the other hand, players born at the end of the year do not have the advantage of being trained by the best coaches and of taking part in highest level competitions (Figueiredo et al., 2009), a fact that increases the probability of them dropping out of sport (Figueiredo et al., 2009; Rebelo et al., 2012), and goes against the principles of development and formation of athletes who are in formative stages (Kirkendall, 2014).

\section{Conclusions}

We concluded that when studying the RAE, we must consider the influence of maturity as a decisive factor in the selection of players, but also the consequences of RAE on the formation of athletes, as nowadays, the older players (belonging to Q1 and Q2) benefit from an accumulation of experience in terms of sporting practice.

Finally, we consider that the problem of the RAE may be counteracted by the responsible technicians of the sports clubs, by introducing other criteria to select players, according to formative objectives, in such a way that priority is given to the search for sporting talent rather than achieving short-term results. Along this line, it is necessary to guarantee to all young players the possibility of being part of the most advanced teams in each category, depending on their talent and not on their chronological age. To this end, competitions should be organized according to the child's sport expertise level, with higher level teams playing against their equals. Thus, the number of players who drop out of school sport practice could be reduced, as the fact that they compete against other players of the same level 
would permit avoiding exaggerated results, and the children would not become discouraged.

To conclude, we must emphasize that the present investigation was a preliminary study, due to the fact that the sample was reduced, considering only soccer players of amateur clubs and the same region. For this reason it would be justified to carry out comparative studies between amateur and professional clubs. Future studies analyzing the influence of RAE on the team's expertise level in each category, are necessary to expand knowledge in this area.

\section{References}

Arrieta H, Torres-Unda J, Gil SM, Irazusta J. Relative age effect and performance in the U16, U18 and U20 European Basketball Championships. J Sports Sci, 2016; 34(16): 1530-1534; doi:10.1080/02640414.2015.1122204

Augste C, Lames M. The relative age effect and success in German elite U-17 soccer teams. J Sports Sci, 2011; 29(9): 983-987; doi:10.1080/0240414.2011.574719

Delorme N, Raspaud M. The relative age effect in young French basketball players: a study on the whole population. Scand J Med Sci Sports, 2008; 19: 235-242

Díaz del Campo DG, Pastor-Vicedo JC, González-Víllora S, Contreras-Jordán OR. The relative age effect in youth soccer players from Spain. J Sports Sci Med, 2010; 9: 190-198

Ericsson KA, Charness N, Feltovich P, Hoffman RR. Cambridge handbook of expertise and expert performance. Cambridge: Cambridge University Press; 2006

Figueiredo AJ, Goncalves CE, Coelho E, Silva MJ, Malina RM. Youth soccer players, 11-14 years: maturity, size, function, skill and goal orientation. Annals Hum Bio, 2009; 36:60e73

Gil SM, Badiola A, Bidaurrazaga-Letona I, Zabala-Lili J, Gravina L, Santos-Concejero J, Granados C. Relationship between the relative age effect and anthropometry, maturity and performance in young soccer players. J Sports Sci, 2014; 32: 479-486; doi:10.1080/02640414.2013.832355

Gil SM, Ruiz F, Irazusta A, Gil J, Irazusta J. Selection of young soccer players in terms of anthropometric and physiological factors. J Sports Med Phys Fit, 2007; 47(1): 25-32

González-Víllora S, Pastor-Vicedo JC, Cordente D. Relative Age Effect in UEFA Championship Soccer Players. J Hum Kinet, 2015; 47: 237-248. http://doi.org/10.1515/hukin-2015-0079

Gutierrez D, Pastor JC, González S, Contreras OR. The relative age effect in youth soccer players from Spain. J Sports Sci Med, 2010; 9: 190-198

Haddad HA, Simpson BM, Buchheit M, Salvo VD, Mendez-Villanueva A. Peak match speed and maximal sprinting speed in young soccer players: Effect of age and playing position. Int J Sports Psysiol Perfor, 2015; 10: 888-896. http://doi.org/10.1123/ijspp.2014-0539

Helsen WF, Van Winckel J, Williams AM. The relative age effect in youth soccer across Europe. J Sports Sci, 2005; 23: 629-636

Idafe J, Matthew GP. Relative age effect in Spanish association football: Its extent and implications for wasted potential. J Sports Sci, 2008; 26: 995-1003

Kirkendall DT. ScienceDirect The relative age effect has no influence on match outcome in youth soccer. J Sport Health Sci, 2014; 3(4): 273-278. http://doi.org/10.1016/j.jshs.2014.07.001

Kraemer HC, Kupfer DJ. Size of treatment effects and their importance to clinical research and practice. Biol Psychiatry, 2006; 59(11): 990-996

Lovell R, Towlson C, Parkin G, Portas M, Vaeyens R, Cobley S. Soccer player characteristics in English lower-league development programmes: The relationships between relative age, maturation, anthropometry and physical fitness. PloS One, 2015; 10(9). http://doi.org/10.1371/journal.pone.0137238

Musch J, Grondin S. Unequal competition as an impediment to personal development: A review of the 
relative age effect in sport. Dev Rev, 2001; 21: 147-167

Nolan JE, Howell G. Hockey success and birth date: The relative age effect revisited. Int Rev Soc Sport, 2010; 45: 507-512; doi:10.1177/1012690210371560

Okazaki FHA, Keller B, Fontana FE, Gallagher JD. The relative age effect among female Brazilian youth volleyball players. Res Quar Exerc Sport, 2011; 82(1): 135-139; doi:10.1080/02701367.2011.10599730

Rebelo A, Brito J, Maia J, Coelho-E-Silva MJ, Figueiredo AJ, Bangsbo J, Malina RM, Seabra A. Anthropometric characteristics, physical fitness and technical performance of under-19 soccer players by competitive level and field position. Int J Sports Med, 2012; 34: 312e7

Romann M, Fuchslocher J. Influence of the selection level, age and playing position on relative age effects in Swiss Women's soccer. Talent Dev Excell, 2011; 3(2): 239-247

Saavedra M, Gutiérrez Ó, Galatti L, Fernández JJ. Relative age effect in lower categories of FIBA basketball world championships (1979-2011). [In Spanish]. Cuadernos de Psicología Del Deporte, 2015; 15(3), 237-242

Sallaoui R, Chamari K, Chtara M, Manai Y, Ghrairi M, Belhaouz M, Baroon A. The relative age effect in the 2013 FIFA U-17 Soccer World Cup competition. Am J Sports Sci, 2014; 2: 35-40 doi:10.11648/j.ajss.20140202.15

Till K, Cobley S, Wattie N, O'Hara J, Cooke C, Chapman C. The prevalence, influential factors and mechanisms of relative age effects in UK Rugby League. Scand J Med Sci Sports, 2009; 20: 320-329 doi:10.1111/j.1600-0838.2009.00884.x

Van den Honert R. Evidence of the relative age effect in football in Australia. J Sports Sci, 2012; 30: 1365e74

Ward P, Hodges NJ, Williams AM, Starkes J. Deliberate practice and expert performance: Defining the path to excellence. In AM Williams and N Hodges (Eds.), Skill acquisition in sport: Research, theory \& practice. London: Routledge, 231-258; 2004

Ward P, Williams AM. Perceptual and cognitive skill development in soccer: The multidimensional nature of expert performance. J Sport Exerc Psychol, 2003; 25: 93-111

\section{Corresponding author:}

\section{Alba Práxedes Pizarro}

Av/Universidad s/n. 10003 - Cáceres (Spain)

Telephone Number: +34 927257461

Fax Number: +34 927257461

E-mail: alba51991@gmail.com 